\title{
Self-Powered Sensors for Monitoring of Highway Bridges
}

\author{
Edward Sazonov, Member, IEEE, Haodong Li, Member, IEEE, Darrell Curry, and Pragasen Pillay, Fellow, IEEE
}

\begin{abstract}
The task of structural health monitoring (SHM) of aging highway bridges and overpasses is important not only from the point of preventing economic losses from traffic delays and detours but also is a matter of preventing catastrophic failures and loss of human life. In recent years, wireless sensor technologies have been used extensively to develop SHM platforms for bridges. A limitation of wireless sensors is the finite life span of batteries and high cost of battery replacements, which make such systems prohibitively expensive in many cases. Energy harvesting is a solution capable to alleviate this problem. A novel wireless sensor system is presented that harvests vibrations of the bridge created by passing traffic, which is converted into usable electrical energy by means of a linear electromagnetic generator. Utilization of an electromagnetic generator allows harvesting of up to $12.5 \mathrm{~mW}$ of power in the resonant mode with the frequency of excitation at $3.1 \mathrm{~Hz}$, in this particular design. The novelty of the system also includes tight integration of the power generator and a smart algorithm for energy conversion that switches between the low-power mode and the impedance matching mode. Finally, results of field experiments are presented in which the wireless system is operated exclusively by the harvested energy of vibration on a rural highway bridge with low traffic volume.
\end{abstract}

Index Terms-Energy harvesting, structural health monitoring, wireless sensors.

\section{INTRODUCTION}

$\mathbf{T}$ HE need for structural health monitoring (SHM) of aging highway bridges and overpasses is well established in the literature [1]-[3]. In 2006, the Federal Highway Administration (FHWA) listed $25.8 \%$ of the nation's 599,766 bridges either as structurally deficient or functionally obsolete [4]. The FHWA names two main reasons for deterioration of the transportation infrastructure: rapid aging of the bridges and significant increase in traffic levels, placing the wear and tear on many bridges beyond the levels that they were designed to handle. For example, half of the bridges in the federal interstate system are over 33 years old [5]. The FHWA estimates show that passenger traffic

Manuscript received January 14, 2009; accepted February 19, 2009. Current version published nulldate. This work was supported in part by the Transportation Research Board of the National Academies under Grant NCHRP-IDEA 117. The associate editor coordinating the review of this paper and approving it for publication was Prof. Geoffrey Chase.

E. Sazonov and P. Pillay are with the Department of Electrical and Computer Engineering, Clarkson University, Potsdam, NY 13699 USA (e-mail: esazonov@clarkson.edu; pillayp@clarkson.edu).

$\mathrm{H}$. Li was with the Department of Electrical and Computer Engineering, Clarkson University, Potsdam, NY 13699 USA. He is now with Advanced MotorTech LLC, Largo, FL 33777 USA (e-mail: hli@advancedmotortech.com).

D. Curry was with the Department of Electrical and Computer Engineering, Clarkson University, Potsdam, NY 13699 USA. He is now with DeFelsko Corporation, Ogdensburg, NY 13669 USA (e-mail: currydj@ clarkson.edu).

Digital Object Identifier 10.1109/JSEN.2009.2019333 will increase by $17 \%$ (from 2.7 trillion vehicle miles traveled to 3.1 trillion) by the end of 2010 and truck traffic will increase by $28 \%$. Aging infrastructure and increased traffic levels put more pressure on the issues of bridge maintenance and operational safety. While many of these bridges will remain in service for many years, they need monitoring and rehabilitation. Presently, bridge monitoring is performed through periodic visual inspections. In the tragic example of the I-35 W Mississippi River bridge collapse, the bridge passed a visual inspection not long before failure [6].

Objective monitoring of highway bridges designed to complement or replace visual inspections is the focus for ongoing research. Permanently installed sensors may enable continuous monitoring of the bridge condition and early reporting of changes that may lead to failure [1], [3]. However, the cost of a traditional wired system presents a major obstacle for practical monitoring. For example, [7] reported costs of $\$ 300,000$ per bridge ( $\$ 5000$ per installed sensor) to install a monitoring system with 60 accelerometers in California and the cost of the 600-channel monitoring system for Tsing Ma Suspension bridge to be over $\$ 16$ million (over $\$ 27,000$ per channel). Installation of cables and cable conduits is labor intensive and constitutes a significant part of the final cost.

Wireless monitoring systems have many advantages over traditional wired systems. These advantages include low cost of the sensors, ease of installation and maintenance, and ability to be applied to existing highway infrastructure [8]. However, wireless systems typically rely on battery energy sources for operation. Given the potential scale of sensor installations on highway bridges, the cost of periodic battery replacements would constitute a major expense that can be prohibitively high. Energy harvesting could present a potential solution and enable permanent unattended sensor installations. Energy harvesting gained significant interest in recent years due to the widespread availability of inexpensive and low-power RF chipsets and microcontrollers that could form the core of a self-powered sensor system.

One of the most popular technologies is using solar energy for powering remote sensor nodes. As an example, [9] studied issues arising from solar energy harvesting. Unfortunately, solar energy is not the best solution for bridge sensors, which quite often need to be located in places with extremely low light intensities. Other energies targeted for harvesting usually include energy of vibration [10] and wind [11].

Our research focuses on using bridge vibrations created by passing traffic to power a sensor permanently deployed on a highway bridge. Vibration is one of the most accessible ambient energies; vibration levels are substantial at most locations along the span and sensors can be placed in hard-to-reach places or 
even embedded into the structure. Energy harvesting of vibration energy has been utilized in a variety of applications and studied for feasibility of use on bridge structures [10].

Although many options, that include piezoelectric, electrostatic, and electromagnetic [12], [13], can be used for harvesting of vibration energy, the electromagnetic [14] is considered for harvesting the energy of vibration in this paper. Piezoelectric harvesters [15], [16] typically require vibrations in the 100s or $1000 \mathrm{~s}$ of $\mathrm{Hz}$, and thus, are not well suited for low-frequency excitation typical of a highway bridge. For example, the piezoelectric generator reported in [16] produced $0.375 \mathrm{~mW}$ of energy at $120 \mathrm{~Hz}$. The electrostatic method [17] typically is capable of generating just microwatts of energy from high excitation frequencies. As an example, a device with one of the highest reported energy outputs [18] produced $1 \mathrm{~mW}$ at $50 \mathrm{~Hz}$ excitation. Electromagnetic harvesters have a greater potential for scaling to lower frequencies characteristic of bridge vibration. For example, [19] reported an output of $4 \mathrm{~mW}$ at $35 \mathrm{~Hz}$. A very comprehensive review of the various techniques can be found in [12]. The novelty of the proposed design is that it targets power of several milliwatts derived from low-frequency excitations on the order of several $\mathrm{Hz}$ and thus is better suited to harvest low-frequency bridge vibration.

Potential benefits of self-powered wireless sensors are numerous. For example, a simple connectivity sensor can monitor the integrity of welded joints, a temperature/humidity sensor can detect freezing conditions, a strain sensor can monitor load levels, and so on. However, vibration energy harvesting from bridge structures is still in its infancy.

In this paper, we present a novel proof-of-the-principle wireless sensor system powered exclusively from bridge vibrations. This self-powered wireless sensor system potentially can remain on the bridge for a very long time and perform a variety of monitoring tasks. The paper is organized as follows. In Section II-A, several key characteristics of bridge vibrations are highlighted as a source of ambient energy with related design considerations. In Section II-B, the wireless sensor platform is presented and its power requirements are analyzed. In Section II-C, an analysis of energy available for harvesting is performed in a vibrating spring-mass system and a method is proposed for selecting a natural frequency with highest power output. In Section II-D, a proof-of-the-principle design of a linear energy harvester is presented. In Section III, the testing of the proposed wireless sensor system on a State Route 11 bridge in Potsdam, NY, USA, is presented. Finally, discussion and conclusion are provided in Sections IV and V, respectively.

\section{METHODS}

\section{A. Characteristics of Bridge Vibration}

The RT11 Bridge in Potsdam, NY (Fig. 1), was selected for the experiments. This is a three simple span steel-girder bridge. About one-third of the span at the northern end of the bridge is easily accessible from the ground. This location has been used to study the characteristics of traffic-induced vibration.

Four wireless accelerometers based on Wireless Intelligent Sensor and Actuator Network (WISAN) [8] have been installed along the span starting at the support and with a distance of 4

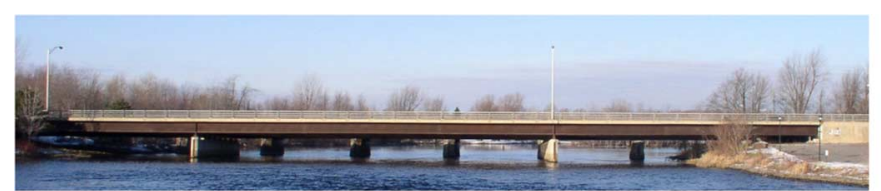

(a)

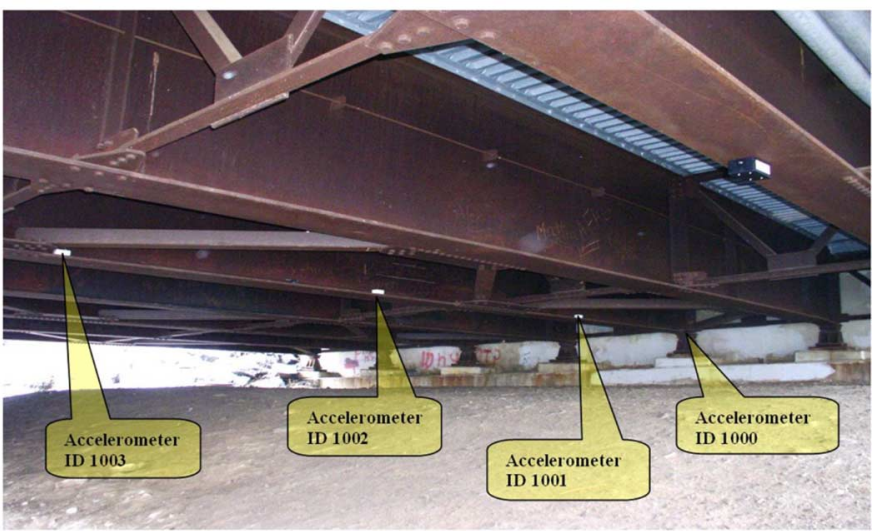

(b)

Fig. 1. (a) Side view of the bridge. (b) Sensor locations for studying bridge vibration along the span.

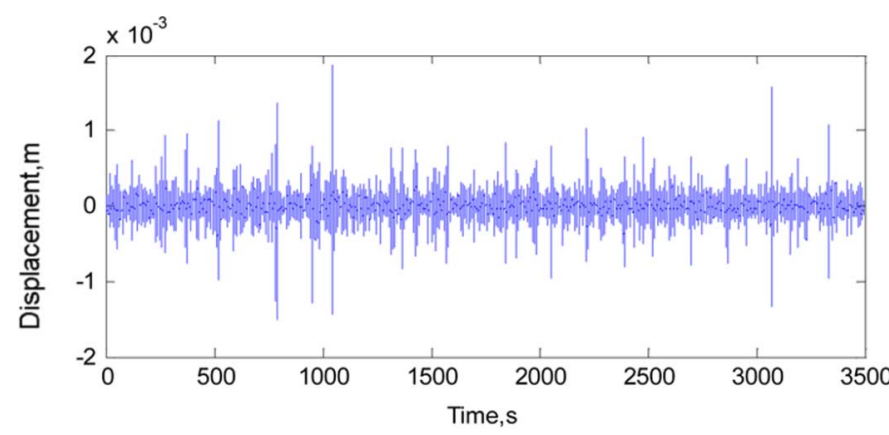

(a)

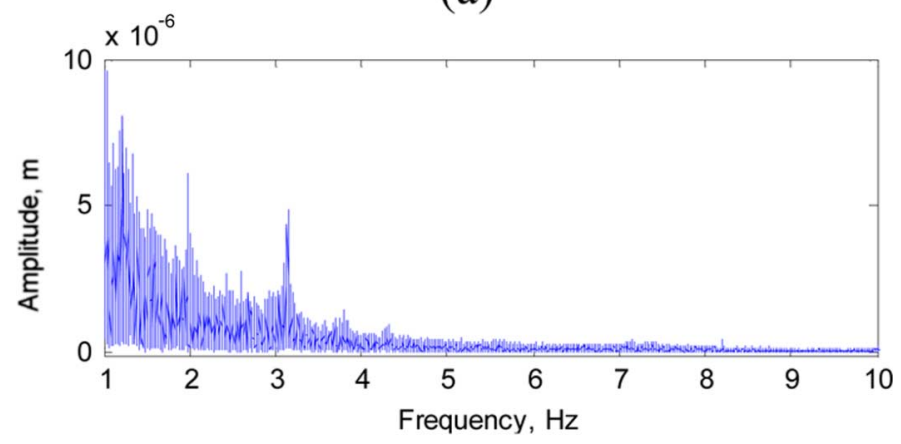

(b)

Fig. 2. (a) Time series and (b) frequency spectrum of girder displacement.

$\mathrm{m}(13.5 \mathrm{ft})$ between the sensors, which corresponds to approximately $33 \%$ of the total span length [Fig. 1(b)].

The time series of acceleration from the accelerometer 1003 was double integrated and high-pass filtered with cutoff frequency of $1 \mathrm{~Hz}$ to obtain time histories of displacement [Fig. 2(a)] and amplitude spectrum [Fig. 2(b)].

Several key observations can be made from this experiment. First, bridge vibrations can be characterized as highly nonsta- 


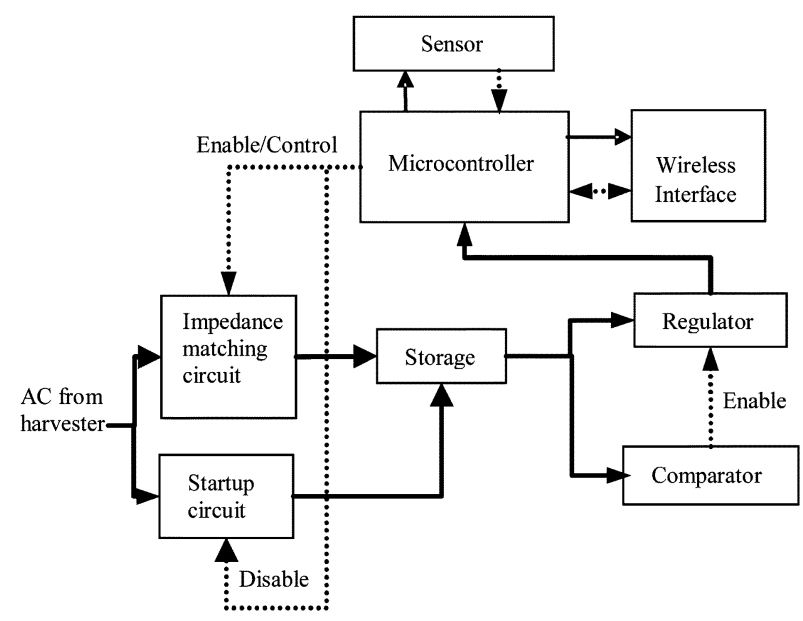

(a)

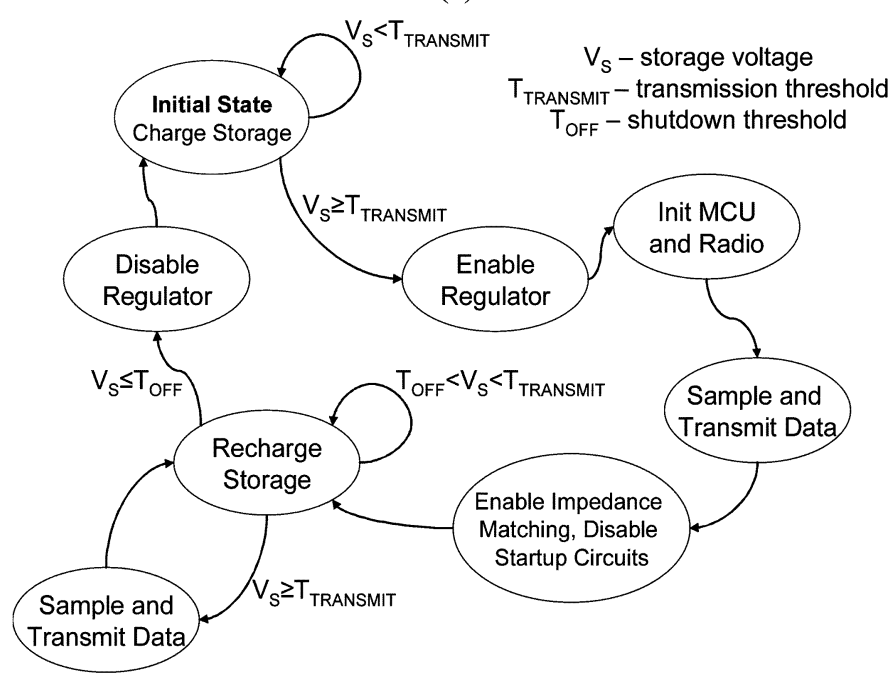

(b)

Fig. 3. (a) Block diagram and (b) state diagram of a wireless sensor node.

tionary with traffic excitation creating bursts of vibration that persist for several seconds and very low levels of vibration between the bursts. Second, vibration levels at supports are minimal and reach the maximum at the middle of the span. Third, the natural frequencies of vibration excited by traffic will depend on structural geometry. Fourth, the amplitude of displacement at a certain frequency depends on a specific location along the girder and may require modal analysis [20] for optimal selection of fundamental frequencies used for harvesting.

\section{B. Architecture and Power Requirements of Wireless Sensor Nodes}

The wireless sensor nodes perform the useful tasks of SHM. The power requirement of a sensor node depend both on the type of utilized sensor and architecture of the node and in turn define power requirements for the energy harvester.

The architecture of a wireless sensor node used in our experiments is presented in Fig. 3(a). The central part is a microcontroller, which is responsible for three essential tasks: control of impedance matching and energy conversion circuit, power control of the sensors and reading of the sensor data, and power control of the wireless interface and transmission of sensor readings. An impedance matching energy conversion circuit was designed to maximize energy delivery from the harvester by presenting a near-optimal load to the linear generator. The circuit is based on the principle similar to those used for solar [21] and piezoelectric [22] energy harvesters, which allows an increase in energy output of the energy harvester up to several hundred percent for strong pulses of traffic excitation. The downside is increased leakage current (from 200 to $2000 \mathrm{nA}$ ) due to the energy consumption of the control circuit. A detailed description of the impedance matching circuit goes beyond the scope of this paper and can be found in [23].

The algorithm of operation for the wireless sensor node is defined by the intermittent availability of power and sporadic nature of strong traffic excitation. The diagram in Fig. 3(b) shows state transitions of the sensor node as a function of energy availability. The initial state has all hardware disabled except for the startup circuit and an ultralow power comparator used to monitor the voltage on the storage capacitor. The capacitor can withstand virtually unlimited number of charge-discharge cycles and thus is preferable to a rechargeable battery. When the storage voltage reaches a threshold, the voltage regulator powers the microcontroller. The microcontroller initializes the system, samples the sensor data, and transmits the reading over the radio link. At the same time, the microcontroller disables the startup circuit and enables the impedance matching circuitry. The storage is then continuously recharged using impedance matching and upon reaching the transmission threshold another sensor reading and transmission are performed. If the harvested energy is no longer available, then the node transitions into the initial state. Such modes of operation allows the harvesting of significantly higher amount of energy from pulses of excitations created by heavy traffic by utilizing impedance matching and at the same time enables operation at low excitation levels where energy costs of running active energy conversion are not justified.

Practically, the wireless sensor node is built based on a microcontroller from MSP430F2xxx series [24], which features low power consumption as well as very quick startup time when using an RC oscillator. The wireless interface is based on a 2.4 GHz chip from Nordic Semiconductors [25]. The sensor node design allows the interfacing of a variety of analog digital sensors through utilization of built-in 10-bit ADC interface and SPI/I2C interfaces.

For this study, we utilized an analog temperature sensor TC1047 from Microchip Technology [26], which features a low supply current of $35 \mu \mathrm{A}$. Temperature is often used for the compensation of material properties and thus is an important parameter in many methods of SHM.

The energy requirements of a sensor node can be expressed as follows: $E_{\mathrm{T}}=\left(M_{\mathrm{S}}+M_{\mathrm{R}}+S+R_{\mathrm{S}}+R_{\mathrm{T}}\right) / \eta$, where $E_{\mathrm{T}}$ is the total required energy to perform a measurement and a transmission, $M_{\mathrm{S}}$ is the energy for microcontroller startup, $S$ is the energy consumed by the sensor, $R_{\mathrm{S}}$ is the energy for radio startup, $R_{\mathrm{T}}$ is the energy for a transmission, and $\eta$ is the energy utilization coefficient accounting for losses during conversion. The energy requirements of components of a wireless sensor node assuming operation at $3 \mathrm{~V}$ and $n=0.5$ are shown 
TABLE I

ENERGY REQUIREMENTS BY COMPONENTS OF A WIRELESS SENSOR NODE OPERATING AT $3 \mathrm{~V}$

\begin{tabular}{|l|l|l|l|}
\hline Component & $\begin{array}{l}\text { Current } \\
\text { consumption, } \\
\mathrm{mA}\end{array}$ & $\begin{array}{l}\text { Duration, } \\
\mathrm{ms}\end{array}$ & $\begin{array}{l}\text { Energy, } \\
\mathrm{uJ}\end{array}$ \\
\hline $\begin{array}{l}\text { Microcontroller } \\
\text { startup (8Mhz) }\end{array}$ & 2.7 & 0.03 & 0.486 \\
\hline $\begin{array}{l}\text { Microcontroller } \\
\text { operation } \\
\text { (8Mhz/LPM3/ADC) }\end{array}$ & $\sim 1.0$ & 0.25 & 1.5 \\
\hline Sensor & 0.035 & 0.25 & 0.052 \\
\hline Radio startup & 0.4 & 1.63 & 3.9 \\
\hline $\begin{array}{l}\text { Radio transmission } \\
\text { (6 bytes, 2 Mbps, no } \\
\text { acknowledgements) }\end{array}$ & 11.3 & 0.048 & 3.254 \\
\hline Total & & & 9.192 \\
\hline
\end{tabular}

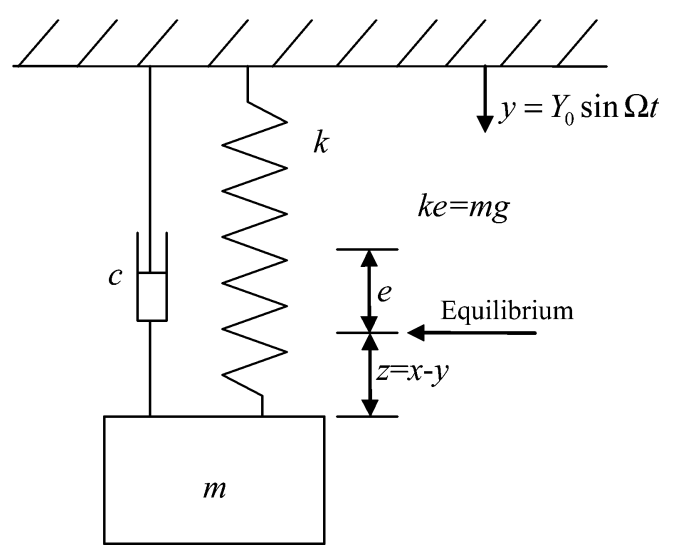

Fig. 4. Spring-mass system with ground force excitation.

in Table I. The total energy required from the energy harvester to generate a single measurement/transmission is approximately $9 \mu \mathrm{J}$, which is spent over duration of approximately $2 \mathrm{~ms}$. Neglecting leakage in energy storage this translates into $4.5 \mathrm{~mW}$ of average power required to keep the sensor running continuously. Since bridge excitation is sporadic and traffic dependent, the intermittent operation of sensor nodes is assumed and the peak power requirement to the energy harvester is $\geq 4.5 \mathrm{~mW}$.

\section{Energy of a Vibrating Spring-Mass System}

The very first step in the design of the linear generator is to estimate energy available for harvesting. Ultimately, the harvester cannot produce more electrical energy than that available in the mechanical energy of vibration.

The proposed electromagnetic energy harvester can be modeled as a spring-mass system with damped forced vibration with ground excitation (Fig. 4) [27]. In Fig. 4, $x$ and $y$ are the absolute displacements of the mass and the ground excitation. Extension of the spring is $e$ when the mass is in the equilibrium position, so that $k e=m g$, where $m$ is the oscillating mass; $k$ is the spring stiffness; and $g$ is the acceleration of gravity $9.8 \mathrm{~N} / \mathrm{kg}$. Assuming sinusoidal ground excitation $y=Y_{0} \sin (\Omega t)$, where $Y_{0}$ is the amplitude and $\Omega$ is the frequency, the relative displacement of mass from its equilibrium position is $x$ and extension of the spring is $(e+z)$, where $z=x-y$ is the relative displacement of the mass with respect to the ground. The following differential equations describe the motion of the spring-mass systems:

$$
-k z-c \dot{z}=m \ddot{z}+m \ddot{y}
$$

where $c$ is the damping coefficient. Equation (1) can be rewritten as

$$
\ddot{z}+2 \xi \omega \dot{z}+\omega^{2} z=\Omega^{2} Y_{0} \sin (\Omega t)
$$

where $\omega=\sqrt{k / m}$ is the natural frequency of the spring-mass system, and $\zeta=c / 2 \sqrt{\mathrm{km}}$ is the damping ratio. The particular solution to (2) that represents a steady-state response of the system is given by

$$
z=Z_{0} \sin (\Omega t-\psi)
$$

where $Z_{0}=Y_{0} r^{2} /\left(\sqrt{\left(1-r^{2}\right)^{2}+(2 \xi r)^{2}}\right)$, and $\tan \psi=$ $2 \xi r /\left(1-r^{2}\right)$ and $r=\Omega / \omega$ is the ratio of the excitation frequency to the natural frequency.

To generate electrical energy out of mass displacement, we can utilize permanent magnets as the vibrating mass and mount an electrical coil around the mass. The instantaneous electrical power, $P_{i}$, generated by such system is

$$
P_{i}=c_{e} \dot{z}^{2}
$$

where $c_{e}$ is the portion of the damping attributable to electrical power generation. Thus, the magnitude of the generated power, $\left|P_{i}\right|$, is

$$
\left|P_{i}\right|=c_{e}\left|Y_{0} r^{2} \Omega /\left[\sqrt{\left(1-r^{2}\right)^{2}+(2 \xi r)^{2}}\right]\right|^{2}
$$

and the average power generated in a steady-state response may be written as

$$
\begin{aligned}
P & =m \xi_{e} Y_{0}^{2} r^{4} \Omega^{3} /\left[\left(1-r^{2}\right)^{2}+(2 \xi r)^{2}\right] \\
\xi & =\xi_{e}+\xi_{f}=c / 2 m \omega
\end{aligned}
$$

where $\xi$ is the combined damping coefficient of the system, which consists of $\xi_{e}=c_{e} / 2 m \Omega$ or the electromagnetic damping coefficient due to electromagnetic coupling of coil and the magnet, and $\xi_{f}$ which is the mechanical damping coefficient that accounts for losses due to spring friction, air resistance, etc.

The output voltage $u$ and current $i$ generated by the electromagnetic coupling of mass displacement can be described by the following equations:

$$
\begin{aligned}
u & =\phi \dot{z}-i\left(R_{c}+j \omega L_{c}\right)=i R_{L} \\
F_{e} & =\phi i=c_{e} \dot{z}
\end{aligned}
$$

where $F_{e}$ is the force generated by the electromechanical coupling, $R_{c}$ and $L_{c}$ are the resistance and inductance of the coil, respectively, $R_{L}$ is the resistance of generator's load, $\omega$ is the 
frequency of oscillation, $\phi$ is the total flux of the coil, and the electrically generated force is

$$
F_{e}=\phi^{2} \dot{z} /\left[R_{L}+R_{c}+j \omega L_{c}\right] .
$$

The electrically generated damping $c_{e}$ can be expressed as

$$
c_{e}=\phi^{2} /\left[R_{L}+R_{c}+j \omega L_{c}\right] .
$$

At low frequencies of vibration characteristics for highway bridges, the inductive impedance of the coil is significantly lower than the resistive impedance and thus can be neglected, resulting in the following equation for the electrically generated damping ratio:

$$
\xi_{e}=\phi^{2} / 2 m \Omega\left(R_{L}+R_{c}\right) .
$$

Assuming ground excitation at exactly the resonant frequency $(\omega=\Omega)$ and substituting from (12) into (6), the total electrically generated power is given as

$$
P=\phi^{2} Y_{0}^{2} \Omega^{2} / 8 \xi^{2}\left(R_{L}+R_{c}\right) .
$$

Generated power is an important factor in the design of an electromagnetic harvester. Another equally important consideration is the output voltage, which should be sufficiently high to allow for operation of energy conversion electronics. The estimation of the output voltage can be performed by computing the ideal potential of the coil

$$
E=\phi Y_{0} \Omega / 2 \sqrt{2} \xi
$$

Equation (13) defines the electrical power harvested from a vibrating spring-mass system in the steady state. The harvested power is proportional to the square of the excitation frequency $\Omega^{2}$ and to the square of excitation displacement $Y_{0}^{2}$; it is also inversely proportional to the damping ratio square $\xi^{2}$, which, in turn, is inversely proportional to $\sqrt{\mathrm{km}}$, which means that increasing the mass and spring stiffness allows more electrical power to be harvested.

Equations (6) and (13) are instrumental in estimating the frequency at which the harvester will achieve the highest power output. The parameters of the generator can be chosen to maximize power delivery and match excitation provided by the bridge. Specifically, the excitation frequency $w$ should be chosen from the set $\left\{w_{i}\right\}, i=1 \cdots N$, where $N$ is the number of natural frequencies present in the bridge and parameters $\Omega, \xi_{e}$, and $\xi$ chosen to bring the power generation to the near-optimal level.

The generator will produce its peak power when the excitation frequency $w$ is equal to the resonant frequency of the generator $\Omega$. Indeed, the critical points obtained by taking a derivative of (6) and setting $d P / d w=0$ are $\pm \sqrt{\left(2 \Omega^{2}-2 w^{2}\right) / w^{2}} / 2$. Thus, the natural frequency of the generator must be set to one of the natural frequencies of the bridge. Fig. 5 shows the normalized power available from vibration of RT11 bridge under assumptions of constant displacement mechanical damping and mass, but varying resonant frequency.

The choice of a natural frequency from the set of $\left\{w_{i}\right\}$ requires further analysis. The excitation provided by the traffic is

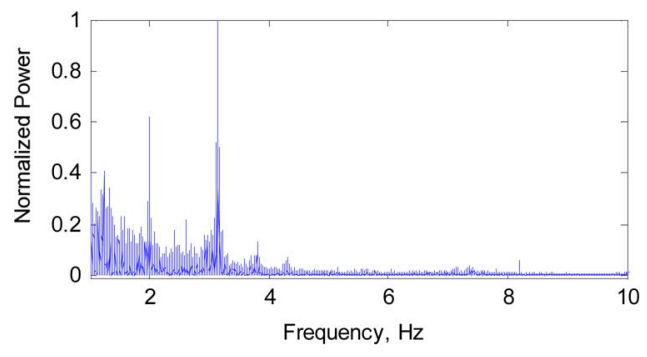

Fig. 5. Power available in the vibration of RT11 bridge.

nonstationary and location dependent, thus a number of simplifications is needed.

First, the excitation provided by traffic is nonstationary and will be subject to substantial transients. A possibility is to apply Fourier analysis of the transient excitation, but the results would be too complex and condition specific. Instead, we suggest using a sufficiently long observation window (for example, Fig. 2 is derived from an hour of observation) that would estimate amplitudes of each natural frequency in an average sense.

Second, the amplitude of vibration varies at different locations of the bridge and depends on type of abutment, proximity to supports, modal number of a specific frequency, and other factors. From this perspective, the behavior of the first bending mode, which has lowest amplitude close to the supports and the maximum amplitude at the middle span is optimal. For example, a harvester designed to operate with the level of excitation present at a $25 \%$ span distance from the supports will be able to function anywhere in the middle $50 \%$ of the span.

Based on these considerations, the natural frequency at $3.1 \mathrm{~Hz}$ was elected for harvesting because our data suggest that this is the first bending mode that in addition can provide the highest power output (Fig. 5).

\section{Aircore Linear Generator}

The design of a simple aircore linear generator follows the consideration of achieving $>4.5 \mathrm{~mW}$ peak power when driven at a frequency of $3.1 \mathrm{~Hz}$. To match the voltage requirements of the wireless sensor nodes, the output voltage of the generator should be greater than $5-6 \mathrm{~V}$. The proposed electromagnetic energy harvester is single phase, high voltage, low current with high coil resistance as a result of the large number of turns. The generator consists of the spring, magnets (mass), and a coil. The magnets and the coil are round resulting in a tubular shape of the generator. The aircore is adopted for decreasing the mechanical damping of the vibration. The base of the generator is mounted to a girder on the bridge and is excited by the vibration of the bridge. For the mass of $0.09 \mathrm{~kg}$, the required spring stiffness is $34 \mathrm{~N} / \mathrm{m}$ resulting in a natural frequency of $3.1 \mathrm{~Hz}$.

Prior to physical implementation, the generator was extensively modeled using finite element analysis. The model was first designed in Autocad [28] and then imported into FLUX [29] for analysis. The flux density created by the magnets reaches values of 200-274 $\mathrm{mT}$ in the coil region. The coil was modeled as a device with 10000 turns of $0.0398 \mathrm{~mm}$ round copper wire (AWG 46), resulting in effective resistance of $67 \mathrm{kOhm}$ and inductance of $34 \mathrm{H}$. The change of the flux in the 


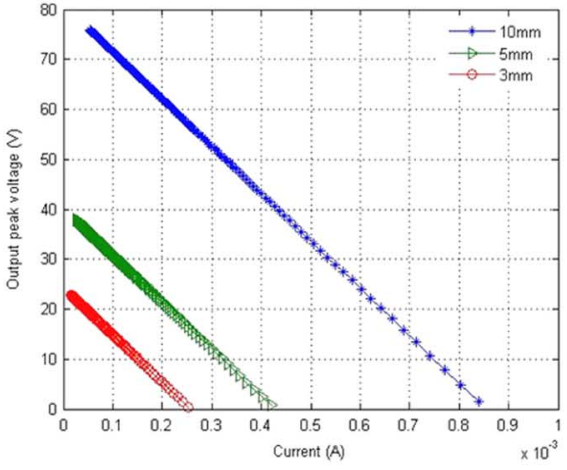

(a)

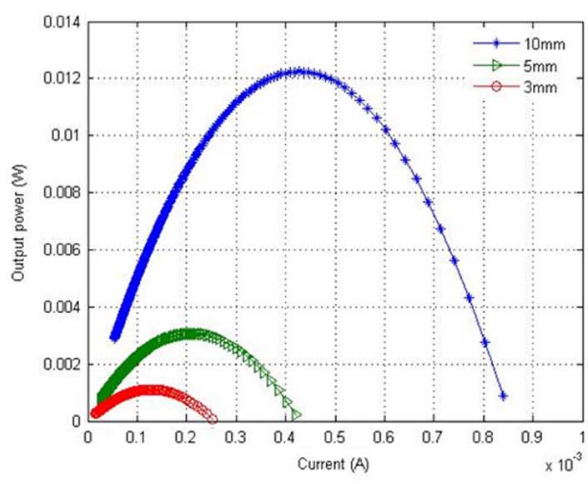

(b)

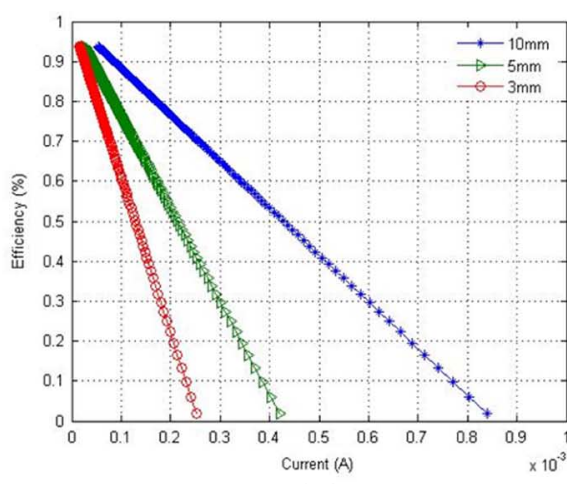

(c)

Fig. 6. Results of finite element modeling under varying excitations: (a) output voltage; (b) power; and (c) efficiency of the simple linear generator.

coil was estimated by accomplishing the transient analysis of FLUX, which resulted in open circuit voltage estimates. Since internal resistance and open circuit voltage of the generator were known, the curves of output voltage, output power, and efficiency under load can be calculated and plotted under varying loads [Fig. 6(a)-(c)]. As results of simulation show, the generator is capable of achieving $12.5 \mathrm{~mW}$ power with $10 \mathrm{~mm}$ displacement of the moving mass, which is sufficient for the wireless sensor.

\section{RESULTS}

The field tests of the self-powered bridge sensor were conducted on RT11 bridge in Potsdam, NY. The goal of the test was to demonstrate completely self-powered operation of the bridge sensor in a short-term test. The sensor was installed on one of the girders in the middle of the northbound lane approximately at one-third of the span length [Fig. 7(a)]. The linear generator and the wireless sensor node were packaged inside of a steel enclosure and chained to the bridge. Wireless transmissions from the self-powered sensor were received by a datalogger device that stored both the temperature reading and the time stamp. The sensor remained on the bridge for duration of one week in September of 2007.

The results of the test are summarized in Fig. 7(b)-(d). Total number of transmissions per each day of monitoring is shown in Fig. 7(b). The average number of transmissions per hour over a week of monitoring is shown in Fig. 7(c). The temperature readings captured during the week of monitoring are shown in Fig. 7(d) (each tick mark corresponds to a 6-h period, the monitoring started at 11 am on September 12, 2007).

\section{DISCUSSION}

Analysis of bridge vibrations presented in this paper shows that the complex nature of structural vibration is one of the defining factors for design of self-powered SHM sensors. The amount of energy available for harvesting heavily depends on the sensor location. In our experiments, the sensor was positioned at approximately $1 / 3$ of the span length and harvesting was conducted at the frequency of the first bending mode shape, which effectively shows that sufficient displacement energy is available in the middle $1 / 3$ of the span. Thus, a fairly large

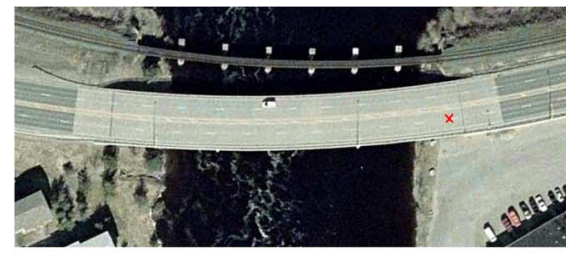

(a)

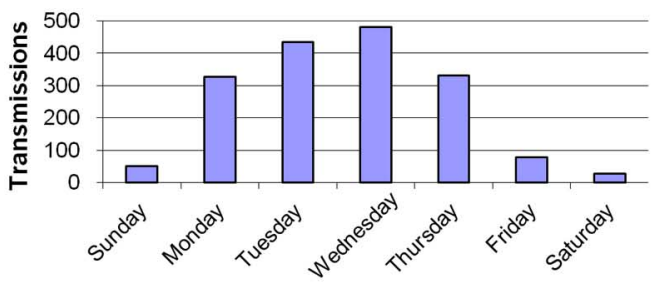

(b)
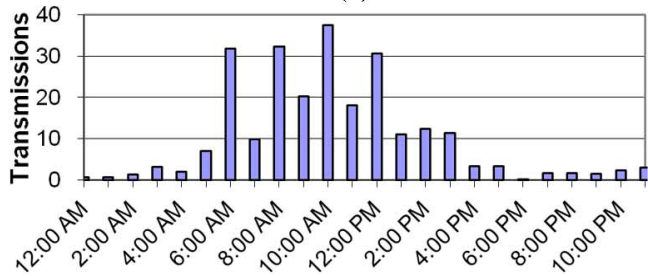

Time of the day, hour

(c)

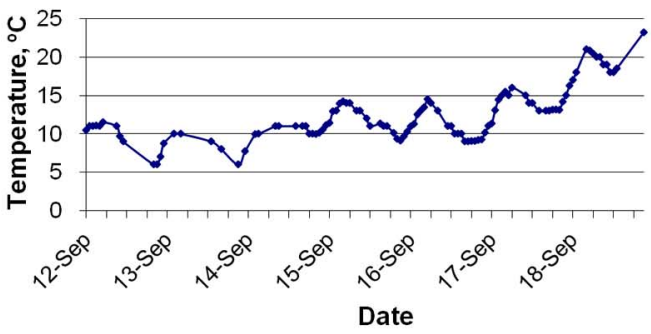

(d)

Fig. 7. (a) Sensor location on the bridge; (b) number of transmissions per day of week; (c) average number of transmissions per time of the day; and (d) temperature readings over a week of monitoring.

portion of the span can be instrumented for practical SHM applications. Energy harvesting closer to supports may need to rely on different mechanisms like harvesting the energy of compression. 
The proposed wireless platform consumes very little power and combines the best of two worlds: an ultralow power design that is well suited for low levels of ambient excitation and an impedance matching energy conversion circuit that can deliver substantially higher energy from excitation from heavy traffic. The power requirements of the temperature sensor used in the experiments are modest; however, they do fit within the range of power requirements characteristic for SHM applications. Specifically, a similar power requirement would be exhibited by continuity sensors for monitoring of welded joints or concrete cracking. Other types of sensors such as ICP accelerometers or strain gauges may require higher accumulated energies. Depending on the desired frequency of updates these sensors may need a linear generator designed with a higher value of vibrating mass.

The conducted analysis of power available for electromagnetic harvesting from bridge vibration allows proper choice of the natural frequency with the highest energy content and estimation of generator parameters. A simple electromagnetic energy harvester with a displacement mass of $0.09 \mathrm{~kg}$ is capable of delivering a peak power of $12.5 \mathrm{~mW}$ at $10 \mathrm{~mm}$ displacement amplitude, which is clearly sufficient for powering of the wireless sensor. At low $3 \mathrm{~mm}$ amplitude of excitation, the generator delivers up to $1 \mathrm{~mW}$ or power at $\sim 10 \mathrm{~V}$ peak voltage, which is sufficient for trickle charging of storage.

A very important conclusion drawn from the field test is that the presented combination of technological solutions proves that self-powered sensors for SHM of bridges is feasible today. The results demonstrate that the prototype system could perform up to 480 measurements per day on a peak day and more than 25 measurements per day on off-peak day. This translates into 1-20 measurements per hour. Such an update frequency is sufficient for a majority of monitoring applications. These results were obtained on a rural bridge with relatively low traffic volume; thus, we would expect better results from heavily loaded city bridges.

The output of the self-powered sensor expressed in transmissions per hour or per day shows a clear dependency on the traffic pattern, which excites the structure. As Fig. 7(b) shows the maximum output is observed during Monday-Friday when the traffic is heavier than weekend traffic, which results in the lowest observed output. Nevertheless, even weekend traffic is sufficient to keep the sensor working. The number of transmissions as a function of time of the day shows a similar dependency. The highest output is observed in the period of 6 am to $4 \mathrm{pm}$. The expressed weekly and daily patterns should be taken into consideration for practical applications of self-powered sensors. Specifically, the desired minimal number of transmissions per hour should be estimated on the worst-case day/ time.

Finally, many of the technical details for individual components of the presented self-powered system could not be included in this paper due to page limitations. An interested reader can find such details in [23], [30]-[32].

\section{CONCLUSION}

This paper presents a prototype of a novel self-powered wireless system for applications of SHM of bridges. The self-pow- ered sensor relies on harvesting the energy of bridge displacements created by passing traffic and produces up to $12.5 \mathrm{~mW}$ of peak power at a very low frequency of excitation of $3.1 \mathrm{~Hz}$ and transient excitations typical of a highway bridge. The conducted theoretical analysis facilitates selection of a natural frequency with the highest energy content and quick estimation of parameters for an electromagnetic harvester. Field tests of the self-powered sensor show the feasibility of the proposed approach for applications of SHM.

\section{REFERENCES}

[1] A. Del Grosso, D. Inaudi, and L. Pardi, "Overview of european activities in the health monitoring of bridges," in Proc. 1st Int. Conf. Bridge Maintenance, Safety Manage. (IABMAS), Barcelona, Spain, 2002, pp. 14-17.

[2] S. Sumitro and M. L. Wang, "Sustainable structural health monitoring system," Struct. Control Health Monit., vol. 12, pp. 445-467, 2005.

[3] M. Q. Feng, Y. Chen, and C. Tan, "Global structural condition assessment of highway bridges by ambient vibration monitoring," in Nondestructive Detection and Measurement for Homeland Security III, A. A. Diaz, A. E. Aktan, H. F. Wu, S. R. Doctor, and Y. Bar-Cohen, Eds. San Diego, CA: SPIE, 2005, pp. 111-125.

[4] FHWA Bridge Programs, Sep. 2008. [Online]. Available: http://www. fhwa.dot.gov/bridge/britab.cfm, Tables of Frequently Requested NBI Information

[5] K. Siggerud, Highway Infrastructure: Physical Conditions of the Interstate Highway System Have Improved, But Congestion and Other Pressures Continue. U.S. and G.A. Office: U.S. General Accounting Office, 2002.

[6] I-35 W Mississippi River Bridge-Wikipedia, the Free Encyclopedia. Sep. 2008. [Online]. Available: http://en.wikipedia.org/wiki/I35W_Mississippi_River_bridge

[7] J. Lynch, A. Sundararajan, K. H. Law, A. S. Kiremidjian, E. Carryer, H. Sohn, and C. R. Farrar, "Field validation of a wireless structural monitoring system on the Alamosa Canyon Bridge," in Prof. SPIE 10th Аnпu. Int. Symp. Smart Structures Mater., San Diego, CA, Mar. 2-6, 2003.

[8] E. Sazonov, K. Janoyan, and R. Jha, "Wireless intelligent sensor network for autonomous structural health monitoring," Smart Structures and Materials 2004: Smart Sensor Technology and Measurement Systems, pp. 305-314, 2004.

[9] V. Raghunathan, A. Kansal, J. Hsu, J. Friedman, and M. Srivastava, "Design considerations for solar energy harvesting wireless embedded systems," in Proc. 4th Int. Symp. Inform. Process. Sensor Netw. (IPSN 2005), 2005, pp. 457-462.

[10] N. G. Elvin, N. Lajnef, and A. A. Elvin, "Feasibility of structural monitoring with vibration powered sensors," Smart Mater. Struct., vol. 15, pp. 977-986, 2006.

[11] S. Priya, "Modeling of electric energy harvesting using piezoelectric windmill," Appl. Phys. Lett., vol. 87, pp. 184101-184103, 2005.

[12] S. P. Beeby, M. J. Tudor, and N. M. White, "Energy harvesting vibration sources for microsystems applications," Meas. Sci. Technol., vol. 17, pp. 175-195, 2006.

[13] S. Roundy, D. Steingart, L. Frechette, P. Wright, and J. Rabaey, "Power sources for wireless sensor networks," Wireless Sensor Netw., pp. 1-17, 2004

[14] P. Glynne-Jones, M. J. Tudor, S. P. Beeby, and N. M. White, "An electromagnetic, vibration-powered generator for intelligent sensor systems," Sens. Actuators: A. Phys., vol. 110, pp. 344-349, 2004.

[15] H. A. Sodano, D. J. Inman, and G. Park, "A review of power harvesting from vibration using piezoelectric materials," in Shock Vibration Digest, 2004, vol. 36, pp. 197-205.

[16] S. Roundy, P. K. Wright, and J. Rabaey, "A study of low level vibrations as a power source for wireless sensor nodes," Comput. Commun., vol. 26, pp. 1131-1144, 2003.

[17] B. Yen and J. Lang, "A variable-capacitance vibration-to-electric energy harvester," IEEE Trans. Circuits Syst. I: Reg. Papers, vol. 53, pp. 288-295, Feb. 2006.

[18] G. Despesse, T. Jager, J. J. Chaillout, J. M. Léger, A. Vassilev, S. Basrour, and B. Charlot, "Fabrication and characterization of high damping electrostatic micro devices for vibration energy scavenging," in Proc. DTIP 2005, pp. 386-390. 
[19] S. P. Beeby, M. J. Tudor, E. Koukharenko, N. M. White, T. O’Donnell, C. Saha, S. Kulkarni, S. Roy, P. NMRC, and I. Cork, "Micromachined silicon generator for harvesting power from vibrations," in Proc. Transducers 2005, Seoul, Korea, 2005, pp. 780-783.

[20] J. He and Z. F. Fu, Modal Analysis. Boston, MA: Butterworth-Heinemann, 2001.

[21] D. P. Hohm and M. E. Ropp, "Comparative study of maximum power point tracking algorithms," Prog. Photovoltaics Res. Appl., vol. 11, pp. 47-62, 2003.

[22] G. Ottman, H. Hofmann, and G. Lesieutre, "Optimized piezoelectric energy harvesting circuit using step-down converter in discontinuous conduction mode," IEEE Trans. Power Electron., vol. 18, pp. 696-703, Mar. 2003.

[23] D. Curry, "Energy harvesting for bridge monitoring," M.S. thesis, Clarksdon Univ., Potsdam, NY, 2008.

[24] Texas Instruments, Sep. 2008. [Online]. Available: www.ti.com

[25] Nordic Semiconductor, Sep. 2008. [Online]. Available: www.nordicsemi.com

[26] Microchip Technology Inc., Sep. 2008. [Online]. Available: www.microchip.com

[27] S. S. Rao, Mechanical Vibrations, 3rd ed. Upper Saddle River, NJ: Prentice-Hall, 1995.

[28] Autodesk, Sep. 2008. [Online]. Available: usa.autodesk.com

[29] Flux FEA Software, Sep. 2008. [Online]. Available: www.fluxsoftware.com

[30] H. Li, "A linear generator powered from bridge vibrations for wireless sensors," Ph.D. dissertation, Clarkson Univ., Potsdam, NY, 2008.

[31] H. Li and P. Pillay, "A linear generator powered from bridge vibrations for wireless sensors," in Proc. IEEE 42nd IAS Annu. Meeting. Conf. (IAS 2007), 2007, pp. 523-529.

[32] H. Li and P. Pillay, "A methodology to design linear generators for energy conversion of ambient vibrations," in Proc. IEEE Ind. Appl. Soc. Annu. Meeting (IAS 2008), 2008, pp. 1-8.

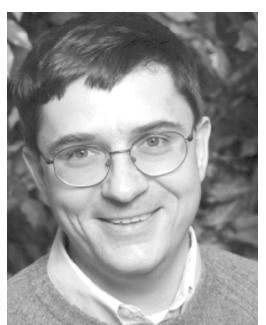

Edward Sazonov (M'02) received the Diploma of Systems Engineer degree from the Khabarovsk State University of Technology, Khabarovsk, Russia, in 1993, and the Ph.D. degree in computer engineering from West Virginia University, Morgantown, in 2002.

Currently, he is an Associate Professor in the Department of Electrical and Computer Engineering, Clarkson University, Potsdam, NY. His research interests include ambient intelligent systems, including sensor network applications in bioengineering and structural health monitoring, self-powered devices and energy harvesting, and ambient and wearable intelligent devices.

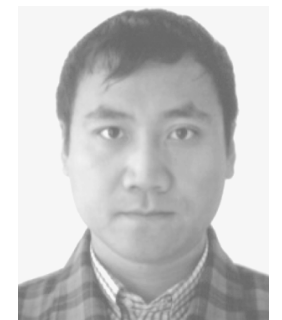

Haodong Li (M'06) received the B.S. and M.S. degrees in electrical engineering from Shenyang University of Technology, Shenyang, China, in 2003, and the Ph.D. degree in electrical engineering from Clarkson University, Potsdam, NY, in 2008.

He has more than three years of experience in design and simulation of innovative machines, drives, controls, and electromechanical components. He is a Senior Engineer in the Advanced MotorTech LLC, Largo, FL. His recent research interests include CAE electrical machine design, modeling and analysis of motor drives, thermal analysis, and coupled-physic field analysis.

Darrell Curry received the B.S. degree in computer engineering and the M.S. degree in electrical engineering from Clarkson University, Potsdam, NY, in 2006 and 2008, respectively.

Currently, he is an Electrical Engineer at DeFelsko Corporation, Ogdensburg, NY.

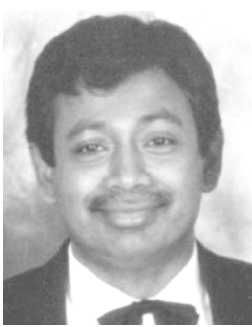

Pragasen Pillay (S'84-M'87-SM'92-F'05) received the B.S. and M.S. degrees in electrical engineering from the University of KwaZulu-Natal, KwaZulu-Natal, South Africa, in 1981 and 1983 , respectively, and the Ph.D. degree in electrical engineering from Virginia Polytechnic Institute and State University, Blacksburg, VA, in 1987, while funded by a Fulbright Scholarship.

From January 1988 to August 1990, he was with the University of Newcastle upon Tyne. From August 1990 to August 1995, he was with the University of New Orleans. From 1995 to 2007, he was a Professor in the Department of Electrical and Computer Engineering, Clarkson University, Potsdam, NY, and held the Jean Newell Distinguished Professorship in Engineering. He is currently on leave from Clarkson at Concordia University in Montreal, Canada. He is also an Adjunct Professor with the University of Cape Town, Cape Town, South Africa. His research interests include modeling, design, and control of electric motors and drives for industrial and alternate energy applications.

Dr. Pillay is a member of the IEEE Power Engineering, IEEE Industry Applications, IEEE Industrial Electronics, and IEEE Power Electronics Societies. He is a member of the IEEE Industry Applications Society (IAS) Electric Machines Committee, Past Chairman of the IEEE IAS Industrial Drives Committee, and Past Chairman of the IEEE Power Engineering Society Induction Machinery Sub-Committee. He currently chairs the Awards Committee of the IEEE IAS Industrial Power Conversion Department. He is a Fellow of the Institution of Electrical Engineers, U.K., and a Chartered Electrical Engineer. He is also a member of the Academy of Science of South Africa. He has organized and taught short courses on electric drives at the Annual Meeting of the IAS. 